Research

\title{
Evaluation of phage assay for rapid phenotypic detection of rifampicin resistance in Mycobacterium tuberculosis
} Sergio Luis Yzquierdo ${ }^{1}$, Dihadenys Lemus ${ }^{1}$, Miguel Echemendia1, Ernesto Montoro*1, Ruth McNerney ${ }^{2}$, Anandi Martin ${ }^{3}$ and Juan Carlos Palomino ${ }^{3}$

\author{
Address: ${ }^{1}$ Instituto de Medicina Tropical "Pedro Kouri", La Habana, Cuba, ${ }^{2}$ London School of Hygiene \& Tropical Medicine, London, UK and \\ Institute of Tropical Medicine, Antwerp, Belgium \\ Email: Sergio Luis Yzquierdo - sergioluis@ipk.sld.cu; Dihadenys Lemus - dlemus@ipk.sld.cu; Miguel Echemendia - mechemendia42@yahoo.es; \\ Ernesto Montoro* - emontoro@ipk.sld.cu; Ruth McNerney - Ruth.Mcnerney@lshtm.ac.uk; Anandi Martin - amartin@itg.be; \\ Juan Carlos Palomino - jcpalomino@itg.be \\ * Corresponding author
}

\section{Published: 21 April 2006}

Annals of Clinical Microbiology and Antimicrobials 2006, 5:II doi:10.1 I86/1476-07| I-5II

This article is available from: http://www.ann-clinmicrob.com/content/5/I/II

(c) 2006 Yzquierdo et al; licensee BioMed Central Ltd.

This is an Open Access article distributed under the terms of the Creative Commons Attribution License (http://creativecommons.org/licenses/by/2.0), which permits unrestricted use, distribution, and reproduction in any medium, provided the original work is properly cited.
Received: 30 January 2006

Accepted: 21 April 2006

\begin{abstract}
Background: Conventional methods for susceptibility testing require several months before results can be reported. However, rapid methods to determine drug susceptibility have been developed recently. Phage assay have been reported as a rapid useful tools for antimicrobial susceptibility testing. The aim of this study was to apply the Phage assay for rapid detection of resistance on Mycobacterium tuberculosis strains in Cuba.
\end{abstract}

Methods: Phage D29 assay was performed on $102 \mathrm{M}$. tuberculosis strains to detect rifampicin resistance. The results were compared with the proportion method (gold standard) to evaluate the sensitivity and specificity of Phage assay.

Results: Phage assay results were available in 2 days whereas Proportion Methods results were obtain in 42 days. A total of 44 strains were detected as rifampicin resistant by both methods. However, one strains deemed resistant by Proportion Methods was susceptible by Phage assay. The sensitivity and specificity of Phage assay were $97.8 \%$ and $100 \%$ respectively.

Conclusion: Phage assay provides rapid and reliable results for susceptibility testing; it's easy to perform, requires no specialized equipment and is applicable to drug susceptibility testing in low income countries where tuberculosis is a major public health problem.

\section{Background}

Tuberculosis (TB) remains a major cause of morbidity and mortality worldwide. It is estimated that about one-third of the world's population is infected with Mycobacterium tuberculosis, more than eight million new cases of active TB occur annually and the estimated global annual mortality from this disease is close to two million people [1]. Multidrug-resistant tuberculosis (MDR-TB), caused by strains resistant to at least isoniazid (INH) and rifampicin (RMP), is considered an emergent disease as well as the consequence of inadequate treatment [2]. WHO has estimated that approximately 460.000 MDR-TB cases occur 
each year [3]. Estimated prevalence of MDR-TB ranges from $0 \%$ in some western countries to $14.2 \%$ in Kazakhstan and Israel, high prevalence has also been observed in the Russian Federation (Tomsk Oblast, 13.7\%); Uzbekistan (Karakalpakstan, 13.2\%), Estonia (12.2\%), China (Liaoning Province, 10.4\% and Henan Province, $7.8 \%)$, Lithuania (9.4\%), Latvia (9.3\%), and Ecuador $(6.6 \%)[4]$.

Currently available techniques for susceptibility testing are culture based, and include the proportion method $(\mathrm{PM})$, resistance ratio and absolute concentration method. Conventional methods require several months before results can be reported. Delays in reporting results lead to prolong an inadequate treatment and may sustain transmission of drug resistant disease. More rapid detection may be obtained by using dyes to indicate bacterial growth such as MTT and Resazurin and a number of assays are currently being evaluated [5]. These methods show high sensitivity and specificity values to detect MDR-TB at lower cost than more conventional approaches [1].

Rapid molecular methods have been developed recently, some of which are commercially available [5]. Based on PCR followed by reverse hybridization to identify either specific mutations or wild-type sequences the INNO-LiPA Rif TB assay (Innogenetics, Ghent, Belgium) detects resistance to rifampicin [6], while the GenoType ${ }^{\circledast}$ MTBDR test (Hain Lifescience Gmbh, Germany) detects resistance to both rifampicin and isoniazid within one working day [7]. However, their expense and the requirement for specialist skills and equipment have prevented their adoption in countries with less favorable living conditions, where $\mathrm{TB}$ is an important health problem.

Mycobacteriophages (phages) were initially investigated as tools for investigating resistance to anti-tuberculosis drugs over 25 years ago $[8,9]$. More recently mycobacteriophage-based techniques have been reported for detection of viable bacilli in clinical specimens as well as for antimicrobial susceptibility testing $[10,11]$. Phages are unable to replicate in the presence of drugs such as RMP that disrupt the mechanism of replication of the host bacteria. However, in drug resistant strains replication can proceed. The resulting phage can be visualized on indicator plates as clear areas (plaques) within a lawn of fast growing mycobacteria [12]. This ingenious method, which does not require specialist laboratory skills or sophisticated equipment, appears to offer robust detection of RMP resistance [13]. Initial reports suggested that resistance to rifampicin could be detected in 4 days [10], but this has since been reduced to less than 48 hours [14]. Furthermore, the assay is available as a commercial diagnostic kit as well as an 'in-house' version [15].
The aim of this study was to apply the Phage assay for rapid detection of RMP resistance on $M$. tuberculosis strains in Cuba.

\section{Methods \\ Strains}

A total of $102 \mathrm{M}$. tuberculosis strains from the collection at the Tuberculosis National Reference Laboratory of Institute de Medicina Tropical "Pedro Kourf" were studied in a blinded manner. Two M. tuberculosis reference strains were used as control of the assay, M. tuberculosis $\mathrm{H}_{37} \mathrm{Rv}$ rifampicin sensitive (ATCC 27294) and M. tuberculosis (ATCC 35838) rifampicin resistant. Mycobacterium smegmatis mc $^{2} 155$ was used to produce indicator plates.

\section{Indicator plates}

Indicator plates were produced as described previously [16]. One hundred microliters of M. smegmatis $\mathrm{mc}^{2} 155$ which was stored in Middlebrook $7 \mathrm{H} 9$ (Difco) at $-70^{\circ} \mathrm{C}$, was spread on a plate which contained $1.5 \%$ agar (Difco) with Middlebrook $7 \mathrm{H} 9$ and $10 \%$ oleic acid albumin dextrose catalase (OADC; Difco). The plate was incubated for three days at $37^{\circ} \mathrm{C}$ and then, one colony was taken and placed in $300 \mathrm{~mL}$ of Middlebrook 7H9 with 10\% OADC and incubated for 2 days at $37^{\circ} \mathrm{C}$. To prepare the plates $10 \%$ stationary phase $M$. smegmatis culture $(100 \mathrm{~mL})$ was added in a medium which contained $15 \mathrm{~g}$ agar (1.5\%) and $800 \mathrm{~mL}$ of Middlebrook 7H9 with $100 \mathrm{~mL} \mathrm{OADC} \mathrm{(10}$ $\%)$. Then approximately $25 \mathrm{~mL}$ of this mix was poured onto Petri dishes. Once set, the indicator plates were stored for up to 2 weeks at $4^{\circ} \mathrm{C}$.

\section{Phage}

Mycobacteriophage D29 was obtained as described previously [16]. One hundred microliters of mycobacteriophage which were stored in Middlebrook $7 \mathrm{H} 9$ with $10 \%$ OADC and $\mathrm{ImM} \mathrm{CaCl}_{2}$ at $4^{\circ} \mathrm{C}$ were spread in an indicator plate and incubated overnight at $37^{\circ} \mathrm{C}$. Ten milliliters of Middlebrook $7 \mathrm{H} 9$ with $10 \%$ OADC and $\mathrm{ImM} \mathrm{CaCl} \mathrm{Cl}_{2}$ were added and incubated overnight at $37^{\circ} \mathrm{C}$. Then, the medium was filtered through a sterile $0.45 \mu \mathrm{m}$ filter and stored in $0.1 \mathrm{~mL}$ at $4^{\circ} \mathrm{C}$ for as long as 6 months. The mycobacteriophage stock was quantified by pipetting 10 $\mu \mathrm{L}$ aliquots of serial dilutions (10 fold) on an indicator plate and the titre of plaque forming units (pfu) calculated.

\section{Antibiotic}

RMP (Sigma) was made up as stock solution at $1 \mathrm{mg} / \mathrm{mL}$ in dimethylsulfoxide (BDH, England) and stored at $-70^{\circ} \mathrm{C}$ in $0.5 \mathrm{~mL}$ vials until use. Further dilutions were made in Middlebrook $7 \mathrm{H} 9$ with $10 \%$ OADC and $\mathrm{ImM} \mathrm{CaCl}_{2}$. 


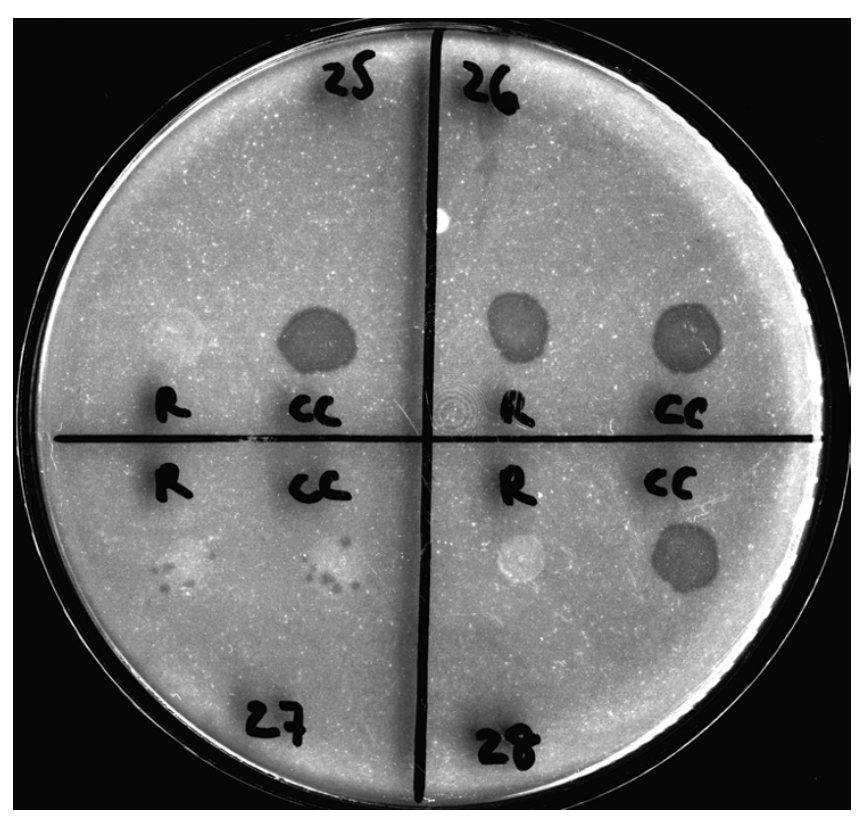

Figure I

Interpretation of the phage assay in the indicator plates. The resistance strains (26 and 27 ) showed lysis on the indicator plates in both the RPM treated and control samples, whereas the sensitive strains (25 and 28 ) had lysis only in the growth (no drug) control.

\section{Phage assay}

The assay was carried out as described Wilson et al. [10]. To reduce cost, the assay was performed in $0.5 \mathrm{~mL}$ vials. Seventy five microliters of $\mathrm{M}$. tuberculosis (McFarland No 1 turbidity) and $75 \mu \mathrm{L}$ of RMP $(20 \mathrm{ug} / \mathrm{mL})$ were placed in vials and incubated during $24 \mathrm{~h}$ at $37^{\circ} \mathrm{C}$. Fifty microliters of mycobacteriophage D29 $\left(10^{8} \mathrm{pfu} / \mathrm{mL}\right)$ were added into the vials and it were incubated for $90 \mathrm{~min}$ at $37^{\circ} \mathrm{C}$. Then, the extracellular viruses were destroyed with $100 \mu \mathrm{L}$ of phagicidal agent ferrous ammonium sulfate at $30 \mathrm{mM}$ (Merck) [11] and finally, the mycobacteriophages were detected by addition $10 \mu \mathrm{L}$ of the samples on the lawn indicator plate after overnight incubation at $37^{\circ} \mathrm{C}$. A growth control containing no drug was included for each strain. The strains were considered resistant if lytic plaques were observed on the indicator plate from those samples treated with RMP; strains were considered susceptible if no plaques were observed following drug treatment.

\section{Proportion method}

The PM was carried out on tubes with Löwenstein-Jensen medium according to the standard procedure with the recommended critical concentration of RMP $40 \mathrm{mg} / \mathrm{mL}$ [17]. This method was used as the gold standard to evaluate the sensitivity and specificity of Phage assay.

\section{Results}

The Phage assay and PM were performed with the purpose to detect RMP resistance on $102 \mathrm{M}$. tuberculosis strains. Phage assay results were available in 2 days whereas PM results were obtained in 42 days. Table 1 shows the results obtained by both methods. Interpretation of the results was easy and clear. The resistant strains showed lysis on the indicator plates in both the RPM treated and control samples, whereas the sensitive strains had lysis only in the growth (no drug) control (Figure 1).

Of 45 strains resistant by the PM, 44 were resistant by the Phage assay. One strain deemed resistant by the PM was susceptible by Phage assay. On the other hand, all the 57 susceptible strains by the PM were also classified as susceptible by Phage assay.

The overall comparison of the Phage assay with the PM produced only one discordant result. The sensitivity of the Phage assay in detecting RMP resistance was $97.8 \%$ whereas the specificity achieved was $100 \%$.

\section{Discussion}

Rifampicin is the most potent sterilizing drug available and a key component for TB treatment. Since RMP resistance is considered a marker of MDR in high level countries, it would be helpful for low resources countries to have a simple and inexpensive test than can rapidly detect resistance to $\operatorname{RMP}[5,18]$.

The diagnosis of MDR-TB is based on in vitro drug susceptibility testing. Conventional culture-based methods are still in routine use in most countries. Susceptibility testing is typically performed on cultures isolated from clinical specimens. These methods requires 3-4 weeks to obtain the results and, combined with the time required for primary isolation, may take several months to obtain the results. Automatic culture systems, such as Bactec 460 have reduced time to several weeks but the machine, the tubes, and the additives are all expensive and generate radioactive waste. Other commercial tests such as the MGIT (mycobacterial growth indicator tube) and molecular tools such as LIPA (line probe assay) have been developed but are expensive and impractical for routine use in resource poor settings [5].

In this study, the Phage assay was performed for rapid detection of RMP resistance in 102 strains of $M$. tuberculosis and the results were compared with the gold standard PM recommended by WHO. Results of the Phage assay were available approximately 40 days earlier than PM that which is significant in terms of patient management [15].

One discrepant result was obtained in which the phage test misidentified a strain as susceptible whereas PM 
Table I: Comparison of Phage assay with Proportion Method to detect Rifampicin-resistant

\begin{tabular}{lcccc}
\hline Proportion Method & \multicolumn{4}{c}{ Phage assay } \\
\cline { 2 - 5 } & Resistant & Susceptible & Sensitivity & Specificity \\
\hline Resistant & 44 & 1 & $97.8 \%$ & $100 \%$ \\
Susceptible & 0 & 57 & & \\
\hline
\end{tabular}

determined it as resistant. When tested by the colorimetric MTT and Resazurin Microtitre Assays [18] this strain showed resistance to RMP $>2 \mathrm{mg} / \mathrm{L}$ by both methods. The failure of D29 to detect resistant bacilli in this sample may be due to experimental error or could be ascribed to technical problems regarding phage replication which will not proceed in bacilli that are dormant or where replication has been disrupted. It is possible that the presence of aggregates of bacteria may have deterred phage access to the rifampicin resistant bacilli in this sample. To date, no strains of M. tuberculosis or M. smegmatis have been identified that lack the binding site for D29 on their cell wall [13]. When reporting results some authors have applied proportional analysis to the numbers of plaque forming units observed. However, most researchers, including us, prefer criteria in which the presence of a simple plaque is indicative of resistance $[14,19,20]$.

The results of the present research are similar to those obtained in Argentina and Brazil by Simboli et al. and da Silva et al. $[19,21]$. Our result showed a good agreement with PM and it confirms the excellent alternative for rapid drug susceptibility testing in poor countries. On the other hand, the assay not only can be applied to RMP but also to INH, ethambutol, pyrazinamide, streptomycin, and ciprofloxacin $[22,23]$. For more rapid screening of patients it has recently been demonstrated that phages can detect RMP resistance directly from smear positive sputum samples [24]. However, further studies are required to determine the sensitivity and reliability of this method.

\section{Conclusion}

The Phage assay doesn't require any specialized equipment or reagents, only basic additional consumable items, such as Petri dishes and pipettes are needed. Besides this, the assay is easy to perform and does not require training in specialist skills. Furthermore, the results of our study indicate the potentiality of the simple and inexpensive Phage assay for control programs in countries with high levels of MDR-TB. The assay could be use, with minor modifications, as a rapid screen for antimicrobial resistance to the principal drugs against TB.

\section{Abbreviations}

TB: Tuberculosis
MDR-TB: Multidrug-resistant tuberculosis

INH: Isoniazid

RMP: Rifampicin

WHO: World Health Organization

PM: Proportion Method

PCR: Polymerase Chain Reaction

OADC: oleic acid albumin dextrose catalase

PFU: plaque performing unit

\section{Authors' contributions}

SLY carried out the Phage assay, participated in the development of the protocol and had substantial contributions in the analysis and interpretation of data. Also, he was involved in the writing of the manuscript. DL carried out the PM and Phage assay, participated in the development of the protocol. Also, she had substantial contributions in the analysis and interpretation of data and she was involved in the revision of the content of the document. ME carried out the PM and supplied the strains from the collection at the Laboratory. EM supervised the design and execution of the study and contributed to the writing and revision of the manuscript. Moreover, he had substantial contributions in the analysis and interpretation of data and gave the final approval of the version to be published. RM, AM and JCP participated in the development of the protocol, they were involved in the revision of the content of document and helped to the writing of the manuscript and they had substantial contributions in the analysis and interpretation of data. All authors read and approved the final manuscript.

\section{Acknowledgements}

We want to thank to Howard Takiff for providing us the mycobacteriophage D29 and M. smegmatis $\mathrm{mc}^{2}$ strain. We also thank to John Allen Houston for his technical assistance. This study was supported by the European Commission RDG (INCO-DEV Programme), project number ICA4-CT200I-10087.

\section{References}

I. Nachega JB, Chaisson RE: Tuberculosis Drug Resistance: A Global Threat. Clin Infect Dis 2003, 36:24-30.

2. Nettleman MD: Multidrug-Resistant Tuberculosis. JAMA 2005, 293:2788-90.

3. World Health Organization: Global tuberculosis control: surveillance, planning, financing. In WHO/HTM/TB/2006.362 Geneva, Switzerland: WHO; 2006.

4. World Health Organization: Anti-tuberculosis drug resistance in the world: Report No.3. The WHO/IUATLD global project on anti-tuberculosis drug resistance surveillance. In WHO/ CDS/TB/2004.343 Geneva, Switzerland: WHO; 2004.

5. Lemus D, Martin A, Montoro E, Portaels F, Palomino JC: Rapid alternative methods for detection of rifampicin resistance in 
Mycobacterium tuberculosis. JAntimicrob Chemother 2004, 54:130-133.

6. De Beenhouwer H, Lhiang Z, Jannes G, Mijs W, Machtelinckx L, Rossau R, Traore H, Portaels F: Rapid detection of rifampicin resistance in sputum and biopsy specimens from tuberculosis patients by PCR and line probe assay. Tuber Lung Dis 1995, 76:425-30.

7. Hillemann D, Weizenegger M, Kubica T, Richter E, Niemann S: Use of the genotype MTBDR assay for rapid detection of rifampin and isoniazid resistance in Mycobacterium tuberculosis Complex Isolates. J Clin Microbiol 2005, 43:3699-3703.

8. Jones WD Jr, David HL: Inhibition by rifampin of mycobacteriophage D29 replication in its drug-resistant host, Mycobacterium smegmatis ATCC 607. Am Rev RespirDis 1971, 103:618-624.

9. David HL, Clavel S, Clement F, Moniz Pereira J: Effects of antituberculosis and anti-leprosy drugs on mycobacteriophage D29 growth. Antimicrob Agents Chemother 1980, 18:357-9.

10. Wilson SM, Al-Suwaidi Z, McNerney R, Porter J, Drobniewski A: Evaluation of a new rapid bacteriophage-based method for the drug susceptibility testing of Mycobacterium tuberculosis. Nat Med 1997, 3:465-468.

II. McNerney R, Wilson SM, Sidhu AM, Harley VS, al Suwaidi Z, Nye PM, Parish T, Stoker NG: Inactivation of mycobacteriophage D29 using ferrous ammonium sulphate as a tool for the detection of viable Mycobacterium smegmatis and $\boldsymbol{M}$ tuberculosis. Res Microbiol 1998, I 49:487-95.

12. David HL, Clavel S, Clement F: Adsorption and growth of the bacteriophage D29 in selected mycobacteria. Ann Inst Pasteur Virology 1980, 131:167-184.

13. McNerney R, Traoré H: Mycobacteriophages and their application to disease control. J App Microbiol 2005, 99:223-233.

14. McNerney R, Kiepiela P, Bishop KS, Nye PM, Stoker NG: Rapid screening of Mycobacterium tuberculosis for susceptibility to rifampicin and streptomycin. Int J Tuberc Lung Dis 2000, 4:69-75.

15. Albert H, Trollip AP, Mole RJ, Hatch JB, Blumberg L: Rapid indication of multidrug-resistant tuberculosis from liquid cultures using FASTPlaqueTE - RIF TM , a manual phage-based test. Int J Tuberc Lung Dis 2002, 6:523-528.

16. McNerney R, Kambashi BS, Kinkese J, Tembwe R, Godfrey-Faussett $P$ : Development of a bacteriophage phage replication assay for diagnosis of pulmonary tuberculosis. J Clin Microbiol 2004, 42:21I5-2I20.

17. Canetti G, Rist N, Grosset JM: Measure de la sensibilité du bacille aux drogues antibacilaire pour la methode des proportions, methodologie, critere du resistanse, results, interpretation. Tuberc Pneumol 1963, 27:217-272.

18. Montoro E, Lemus D, Echemendia M, Martin A, Portaels F, Palomino JC: Comparative evaluation of the nitrate reduction assay, the MTT test, and the resazurin microtitre assay for drug susceptibility testing of clinical isolates of Mycobacterium tuberculosis. JAntimicrob Chemother 2005, 55:500-505.

19. Simbolí N, Takiff H, McNerney R, López B, Martin A, Palomino JC, Barrera L, Ritacco V: In-house phage amplification assay is a sound alternative for detecting rifampin-resistant Mycobacterium tuberculosis in low-resource settings. Antimicrob Agents Chemother 2005, 49:425-427.

20. Gall N, Domínguez J, Blanco S, Prat C, Quesada MD, Matas L, Ausina $\mathrm{V}$ : Utility of an in-house mycobateriophage-based assay for rapid detection of rifampin resistance in Mycobacterium tuberculosis clinical isolates. J Clin Microbiol 2003, 41:2647-2649.

21. Da Silva PA, Boffo MM, De Mattos IG, Silva AB, Palomino JC, Martin A, Takiff HE: Comparison of redox and detection of isoniazid and rifampicin resistance in Mycobacterium tuberculosis. Clin Microbiol Infec 2006, 3:293-6.

22. Eltringham IJ, Wilson SM, Drobniewski FA: Evaluation of a bacteriophages-based assay (Phage Amplified Biologically Assay) as a rapid screen for resistance to isoniazid, ethambutol, streptomycin, pyazinamide and ciprofloxacin among clinical isolates of Mycobacterium tuberculosis. J Clin Microbiol 1999, 37:3528-3532.

23. Ramachandran R, Paramasivan $\mathrm{CN}$ : What is the diagnosis of tuberculosis? Part II; Techniques for drug susceptibility testing. Ind J Tuberc 2003, 50:197-202.

24. Albert H, Trollip A, Seaman T, Mole RJ: Simple, phage-based (FASTPlaque) technology to determine rifampicin resistance of Mycobacterium tuberculosis directly from sputum. Int Tuberc Lung Dis 2004, 8: I I I4- I I I9.
Publish with Biomed Central and every scientist can read your work free of charge

"BioMed Central will be the most significant development for disseminating the results of biomedical research in our lifetime. "

Sir Paul Nurse, Cancer Research UK

Your research papers will be:

- available free of charge to the entire biomedical community

- peer reviewed and published immediately upon acceptance

- cited in PubMed and archived on PubMed Central

- yours - you keep the copyright 